\title{
On the Comparison of Microstructure Characteristics and Mechanical Properties of High Chromium White Iron with the Hadfield Austenitic Manganese Steel
}

\author{
Johnson O. Agunsoye ${ }^{1 *}$, Talabi S. Isaac ${ }^{2}$, Agbeleye A. Abiona ${ }^{1}$ \\ ${ }^{1}$ Department of Metallurgical and Materials Engineering, University of Lagos, Lagos, Nigeria \\ ${ }^{2}$ Department of Materials and Metallurgical Engineering, University of Ilorin, Ilorin, Nigeria \\ Email: *jagunsoye@unilag.edu.ng
}

Received October 7, 2012; revised November 15, 2012; accepted November 27, 2012

\begin{abstract}
In this study, high chromium white iron (HC-Wi) alloy and the Hadfield steel were studied. The microstructure of this high-chromium iron was studied using Metallurgical optical microscopy (OM) and compared to the Hadfield steel. The hardness and unnotched charpy impact strength of the HC-Wi alloy and Hadfield steel were examined at ambient temperature in the as-cast and heat-treated conditions. A pin-on-disc test at linear speed of $1.18 \mathrm{~m} / \mathrm{s}$ and a $10 \mathrm{~N}$ normal load was employed to evaluate the wear behavior of both steel samples. Microstructural results showed that varying the carbon level in HC-Wi alloys can affect the chromium carbide morphology and its distribution in the austenite matrix which leads to considerable changes of the mechanical properties. Abrasion test showed that HC-Wi alloys have superior wear resistance, about three times of the Hadfield steel.
\end{abstract}

Keywords: High Chromium White Iron; Hadfield Steel; Microstructure; Wear

\section{Introduction}

When there was a challenge to develop steel which possesses two extreme properties at the same time, Sir Robert Hadfield invented Hadfield steel in 1882. The idea was to have steel which is tough and at the same time hard. This type of steel with its austenitic matrix has high toughness, high ductility, and high work-hardability. Majority of the cast Hadfield steel are excellent candidates in variety of applications such as: earthmoving, mining, railways, quarrying, dredging and drilling in the oil/gas [1,2].

The global economic recession has continue to place heavy burden on foundries world-wide and Nigeria in particular to look for means of improving their productivity and higher products quality, as well as to strive to achieve the optimum economy in wear industries; in the past decade, the use of carbon steel ball in dry mill grinding has been replaced with in situ ceramic-steel composite synthesis technique to increase the life of the wear parts. In this technique, hard ceramic forming elements are introduced to the molten steel as an alloying element and a more thermodynamically stable reinforcing phase will be formed during solidification by the nucleation and growth mechanism in the parent matrix [3].

"Corresponding author.
One of the most common ceramic reinforcing materials being used in iron base alloys is carbides and among them chromium carbide due to its high hardness of about 1020 - $1835 \mathrm{Hv}$ [4], have proved to be a unique choice to wear resistance of cast high chromium white iron with martensitic microstructure [5,6]. However, less attention has been paid to the research on Hardfield Austenitic Manganese steel.

In general terms, the high chromium iron suitable for wear resisting applications fall within the compositional limits bounded by the austenitic phase field of the ternary liquidus surface of the iron, chromium, carbon diagram. Solidification takes place by a eutectic process The products of the eutectic reaction are austenite and chromium rich carbides of the $\left(\mathrm{FeCr}_{7}\right) \mathrm{C}_{3}$. For high chromium white iron with a $\mathrm{Cr}$ concentration of some 18 - 20 wt $\%$ (hypoeutectic composition), solidification starts with the nucleation of dendritic primary austenite $(\gamma)$, followed by the formation of $\gamma+\mathrm{M}_{7} \mathrm{C}_{3}$ carbide and its morphology have been well documented by several researchers [7]. The HC-Wi alloy has an austenitic matrix structure at ambient temperature with chromium carbide dispersed within the matrix. The wear resistance of this material is achieved at the surface when the abrasive particle or impact load transforms the unstable Austenite to martensite by strain induced mechanism. This phenomenon of Aus- 
tenite transformation to martensite causes increased surface hardness and less wear rate loss. Carbon content plays a significant role in chromium carbide formation and its morphology as well as hardness, impact toughness and wear resistance. In this study, the effect of carbon content on the microstructure, mechanical properties and wear characteristics of HC-Wi has been studied and compared to the Hadfield steel.

\section{Materials}

HC-Wi and Hadfield Steel grade of materials were produced in Nigerian Foundries Limited (NFL), Otta, Nigeria using the charge makeup in Tables 1 and 2 respectively. An Electric Induction Furnace of $500 \mathrm{~kg}$ neutral lined was used for the melting operation and the sample representative taken from the molten bath at $1550^{\circ} \mathrm{C} \mathrm{d}$ and poured into a $\mathrm{CO}_{2}$ sand improvised moulds $(11 \times 11$ $\times 200) \mathrm{mm}$. The charge makeup used in obtaining the specification is tabulated below.

After the first heat from Table 1, a sample representative was taken and casted. For subsequent batches, fine granules of graphite were added in their various compositions of $1.6 \% \mathrm{C}, 2.2 \% \mathrm{C}, 2.7 \% \mathrm{C}$ and $3.3 \% \mathrm{C}$ respectively to the molten bath and the temperature maintained at $1520^{\circ} \mathrm{C}-1543^{\circ} \mathrm{C}$ for 10 minutes to enable the graphite granules dissolve adequately. This process was repeated

Table 1. Charge makeup for HC-Wi.

\begin{tabular}{cccccccc}
\hline \multirow{2}{*}{ Raw Materials Mass (Kg) } & \multicolumn{7}{c}{ Elemental Contribution (\%) } \\
\cline { 3 - 8 } & & C & Si & Mn & P & S & Cr \\
\hline Returns & 156.25 & 0.94 & 0.21 & 0.01 & 0.01 & 0.01 & 7.19 \\
Steel Scraps & 223.21 & 0.09 & 0.09 & 0.04 & 0.02 & 0.02 & 0.00 \\
Fe-Cr & 98.21 & 0.10 & - & - & - & - & 17.68 \\
Fe-Si & 2.23 & - & 0.33 & - & - & - & - \\
Fe-Mn & 4.46 & 0.07 & - & 0.58 & - & - & - \\
Graphite & 3.80 & 0.51 & - & - & - & - & - \\
Total & 500 & 1.55 & 0.63 & 0.63 & 0.03 & 0.03 & 24.87 \\
\hline
\end{tabular}

Table 2. Charge makeup for Hadfield Steel.

\begin{tabular}{ccccccccc}
\hline Charge makeup & & \multicolumn{5}{c}{ Elemental Contribution (\%) } \\
$\begin{array}{c}\text { for Hadfield } \\
\text { SteelRaw Material }\end{array}$ & (Kg) & C & Si & Mn & P & S & Cr \\
\cline { 5 - 8 } Returns & 187.83 & 0.410 & 0.190 & 4.760 & 0.005 & - & 0.570 \\
Steel Scraps & 234.80 & 0.095 & 0.120 & 0.120 & - & - & - \\
Fe-Cr & 7.04 & 0.001 & - & - & - & - & 1.280 \\
Fe-Si & 2.00 & - & 0.300 & - & - & - & - \\
Fe-Mn & 63.40 & 0.140 & - & 9.640 & - & - & - \\
Graphite & 4.93 & 0.66 & - & - & - & - & - \\
Total & 500 & 1.30 & 0.610 & 14.52 & 0.005 & 0.000 & 1.850 \\
\hline
\end{tabular}

for all incremental granules addition. To reduce the tendency for oxidation, $1 \mathrm{Kg}$ of Aluminum Briquette was added to the melt. Besides, Hadfield steel melt was prepared according to ASTM $128 \mathrm{C}$ standard as presented in Table 2.

The overall chemical composition obtained for the 2 heats and 5 batches is presented in Table 3.

A calibrated Hilger Analytical Direct Optical Emission Polyvac Spectrometer E980C with 20 analytical channels was used for the analysis of the chemical composition of the HC-Wi and Hadfield steel. Hadfield steel is difficult to machine due to its work-hardening propensity. Hence, a sample representative was taken from the Hadfield steel molten bath and poured into a $(10.20 \times 10.2 \times 200)$ mm preheated medium carbon steel mould so as to obtain the required $(10 \times 10 \times 50) \mathrm{mm}$ bar for the impact test. This technique was aimed at avoiding the need to machine the samples. To investigate the effect of the heat treatment of Hadfield steel on the properties of $\mathrm{HC}-\mathrm{Wi}$, halves of all the specimens with the size $(10 \times 10 \times 50)$ $\mathrm{mm}$ were solution annealed at $1050^{\circ} \mathrm{C}$ for 30 minutes and then water quenched.

\subsection{Microstructure}

For microstructural analysis, all the as-cast and heat-treated samples were cut from the bottom end, ground with tehrapol-31, then polished using a colloidal suspension of $0.04 \mu \mathrm{m}$ silicon dioxide and then etched in $100 \mathrm{ml}$ alcohol and $3 \mathrm{ml} \mathrm{HNO}_{3}$ acid after polishing using Allegrol with diamond suspension at the Metallographic Laboratory, Department of Mechanical Engineering of the University of Ottawa, Canada. A metallurgical optical microscopy was used to study the microstructures.

\subsection{Mechanical Properties}

Vickers micro hardness of tested samples was measured using Duramin-1 microhardness tester struers. The reported hardness values were the average of five measurements. Charpy unnotched impact test was also carried out on $(10 \times 10 \times 50) \mathrm{mm}$ standard Hadfield and HC-Wi specimens at room temperature. In order to compare the wear resistance of the developed HC-Wi alloys with Hadfield steel, abrasive wear tests were conducted on all

Table 3. Chemical composition of the HC-Wi.

\begin{tabular}{ccccccccccc}
\hline Material & C & Mn & Si & Cr & P & S & Mo & Ni & Al & Fe \\
\hline HC-Wi-1 & 1.55 & 0.63 & 0.63 & 24.87 & 0.03 & 0.03 & 0.02 & 0.01 & 0.01 Balance \\
HC-Wi-2 & 2.22 & 0.63 & 0.62 & 24.60 & 0.03 & 0.03 & 0.01 & 0.01 & 0.01 Balance \\
HC-Wi-3 & 2.73 & 0.59 & 0.60 & 24.20 & 0.03 & 0.03 & 0.01 & 0.015 & 0.02 & Balance \\
HC-Wi-4 & 3.26 & 0.56 & 0.60 & 23.60 & 0.03 & 0.03 & 0.01 & 0.01 & 0.02 Balance \\
$\begin{array}{c}\text { Hadfield } \\
\text { Steel }\end{array}$ & 1.30 & 14.52 & 0.61 & 1.85 & 0.01 & 0.00 & - & - & 0.15 & Balance \\
\hline
\end{tabular}


cast sample in the as-cast and heat-treated conditions using a pin-on-disc wear machine as per ASTM G99-95 Standard. The disc used is En-32 steel hardened to 62 HRC, $200 \mathrm{~mm}$ track diameter and $12 \mathrm{~mm}$ thick with surface roughness of $20 \mu \mathrm{m}$ Ra. The sample with cross section $10 \mathrm{~mm} \times 10 \mathrm{~mm}$ was taken from the fracture impact test and used for the wear test. Applied normal load on all the samples was $10 \mathrm{~N}$ over a sliding distance of 70.8 $\mathrm{m}$ on a fresh 120 grit SiC abrasive paper. Before and after each test, the sample was carefully cleaned with acetone and weighed using an analytical balance with an accuracy of $0.001 \mathrm{~g}$. The relative wear resistance was given by the weight loss of HC-Wi alloy samples related to the weight loss of the heat-treated Hadfield steel sample. The reported values are the average of four test runs on each composition material.

\section{Results and Discussion}

\subsection{Microstructural Analysis}

Figures 1(a)-(d) show the effect of carbon content on the morphology and distribution of primary chromium carbides in HC-Wi alloys in the as-cast condition. When the high chromium molten alloy starts to solidify; chromium carbide nucleation takes place and grows in the melt and crystallizes as coarse primary chromium carbides between the liquidus and solidus temperatures. It has been observed from the data available from Table $\mathbf{3}$ and Equation (1),

$$
\% \text { Carbide }=12.33(\% \mathrm{C})+0.55(\% \mathrm{Cr})-15.2
$$

that as the carbon content of the HC-Wi increases, the amount of chromium carbide increases (Table 4) and primary chromium carbides change from the fairly round, strip into spherical shape and they are distributed more uniformly up to carbon content of 2.73 but further increase in the carbon content decreases the homogeneity of the chromium carbide distribution within the austenitic matrix (Figures 1(b) and 1(c)).

In HC-Wi alloy, due to the presence of $>20 \%$ Chromium in the composition as one of the strongest carbide forming elements in steel compared to iron or manganese (very high affinity of chromium to absorb carbon), chromium reacts with the dissolved carbon of the molten steel resulting to the formation of chromium carbide instead of iron manganese carbide.

In as-cast Hadfield steels, austenite grain boundary steel are surrounded by a continuous network of segregated and brittle (FeMn) ${ }_{3} \mathrm{C}$ shown in Figure 3(a). Solution annealing between the temperature range of $1000^{\circ} \mathrm{C}$ $1050^{\circ} \mathrm{C}$ dissolves these carbides in austenite and subsequently quenching in water prevents the formation $\mathrm{M}_{3} \mathrm{C}$ in grain boundary as shown in Figure 3(b) [9].

In high chromium austenite steel, due to the presence

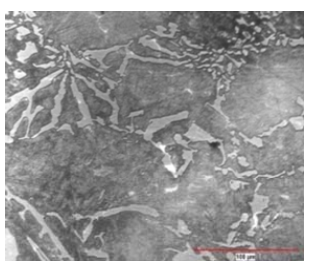

(a)

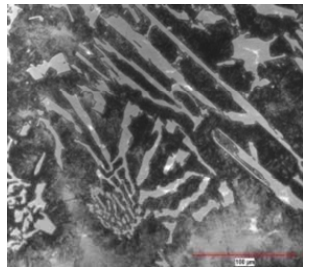

(c)

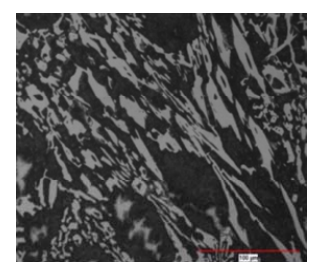

(b)

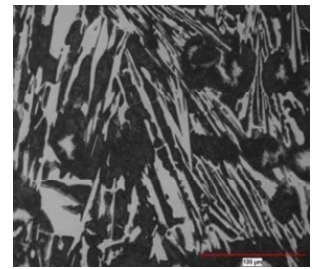

(d)
Figure 1. Optical micrograph of HC-Wi in the as-cast condition. (a) HC-Wi-1 (b) HC-Wi-2 (c) HC-Wi-3 (d) HC-Wi-4.

Table 4. The amount of chromium carbide $\left(\mathrm{Cr}_{3} \mathrm{C}_{7}, \%\right)$ in the as-cast conditions.

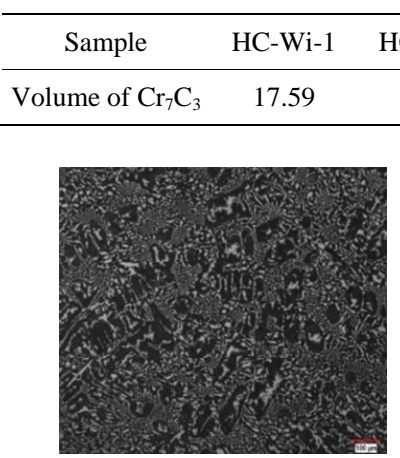

(a)

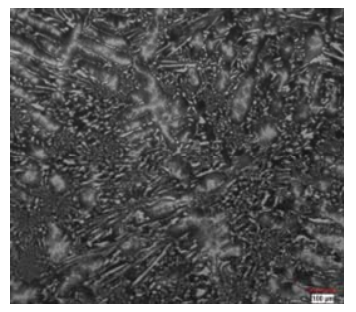

(c)

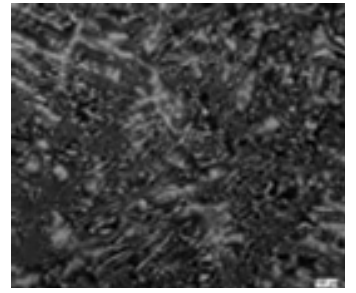

(b)

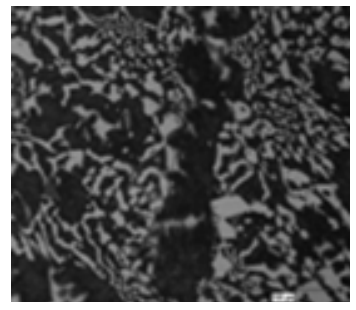

(d)
Figure 2. Optical micrograph of HC-Wi in heat-treated condition. (a) HC-Wi-1 (b) HC-Wi-2 (c) HC-Wi-3 (d) HC-Wi-4.

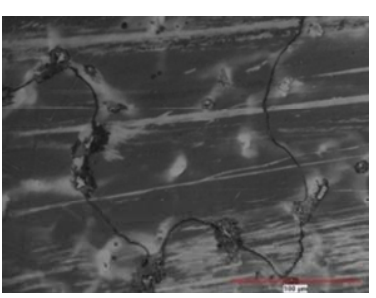

(a)

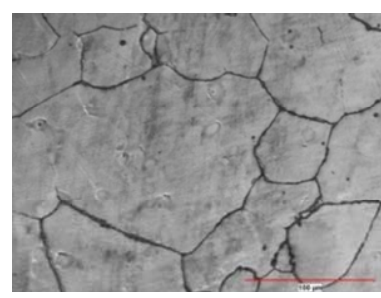

(b)
Figure 3. Optical micrograph of the hadfield steel (a) as-cast condition (b) heat-treated condition. 
of more than $20 \%$ chromium, chromium is one of the strongest carbides forming element in steel compared to iron or manganese (chromium has high affinity for carbon), chromium reacts with the dissolved carbon in the molten steel leading to the formation of a more stable chromium carbides instead of iron manganese carbides. When compared to Figure 3, iron manganese carbides in HC-Wi samples virtually non-existence and form a continuous network of brittle phase around the austenite grains.

\subsection{Mechanical Properties}

Initially measured values of Vickers hardness of all samples in as-cast and heat-treated conditions before the abrasion test are presented in Figure 4. It shows that the hardness of HC-Wi alloys is almost $69 \%$ higher than Hadfield austenitic manganese steel due to the presence of high percentage of extremely hard chromium carbide $\mathrm{Cr}_{3} \mathrm{C}_{7}$ in the microstructure. Solution annealing has less influence on the hardness changes of HC-Wi alloy compared to Hadfield austenitic steel. Hadfield steels contain some segregated hard grain boundary carbide of the form $\mathrm{Cr}_{3} \mathrm{C}_{7}$ within the softer austenite matrix. This is clearly responsible for the increase in overall hardness in the as-cast conditions. Figure 4 also showed that austenite matrix in HC-Wi alloys is more than twice the hardness of the Hadfield steel (in both as-cast and heat-treated conditions).

This considerable increase in austenite hardness is related to the solution of carbon and chromium elements in iron lattice coupled with the precipitation of secondary chromium carbide (Figures 1 and 2) in austenite which strengthens the soft matrix.

Figure 5 shows Charpy unnotched impact toughness of the materials. The main difference in impact energy values before and after the heat treatment was observed in the Hadfield steel and it is due to the dissolution of the

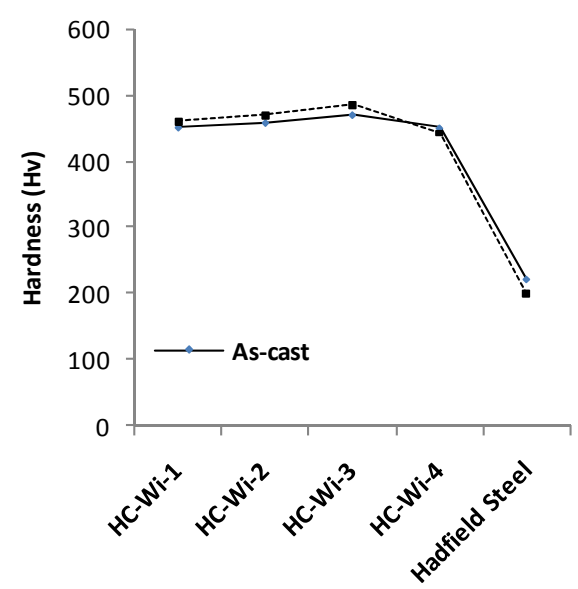

Figure 4. Vickers micro-hardness of as-cast and heat-treated materials.

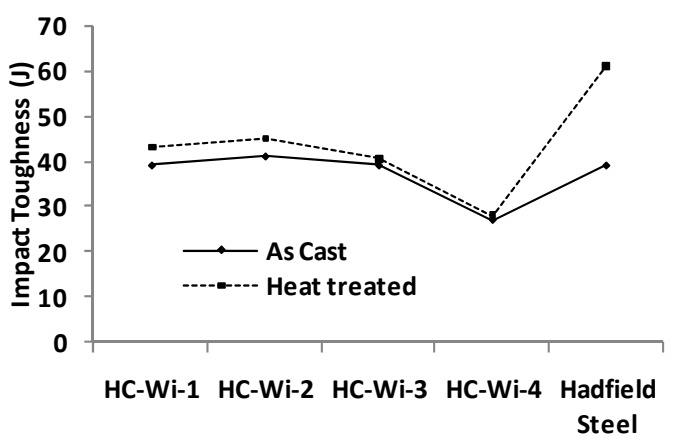

Figure 5. Impact toughness of HC-Wi alloys and Hadfield steel.

brittle carbide, segregated along the austenite grain boundaries in the as-cast condition (Figure 3(a)). These brittle phases with lamellar/acicular morphology along the boundaries cause stress to be built-up in the matrix, leading to dislocation pile up, crack initiation, propagation and crack growth and subsequently low impact toughness of the Hadfield steel in as-cast condition. For HC-Wi alloys, chromium carbide morphology and its distribution both influence significantly the impact energy. HC-Wi-1 composition with uniform distribution of chromium carbide has the highest impact toughness, while the HC-Wi-4 has the lowest impact toughness. As the carbon content increases, the morphologies of the chromium carbides in the matrix also change. The distribution of the chromium carbide influences the mechanical properties of the material.

\subsection{Wear Resistance}

The wear loss of HC-Wi alloys compared to the heattreated Hadfield steel in the as-cast and heat-treated conditions are presented in Figure 6. The predominant wear mechanism in the pin-on-disc abrasion test is micro cutting and surface hardness of the materials plays a significant in determining the wear resistance. Hence, HC-Wi alloys shows remarkable higher wear resistance (3 times) than Hadfield steel due to higher surface hardness caused by the existence of hard carbide phase dispersed within the austenite matrix. Despite the low surface hardness of HC-Wi-3 compared to HC-Wi-4, the wear resistance of HC-Wi-3 is superior and higher than HC-Wi-4 (Figure 6). This is because the carbide distribution in $\mathrm{HC}-\mathrm{Wi}-4$ is heterogeneous (Figure 2(d)). Hence, that the distributions of the hard second phase carbide also affect the wear resistance.

\section{Conclusions}

1) High chromium white iron alloy have superior wear resistance compared to hadfield austenitic manganese steel due to the presence of hard chromium carbide distributed within the matrix of the microstructure. 


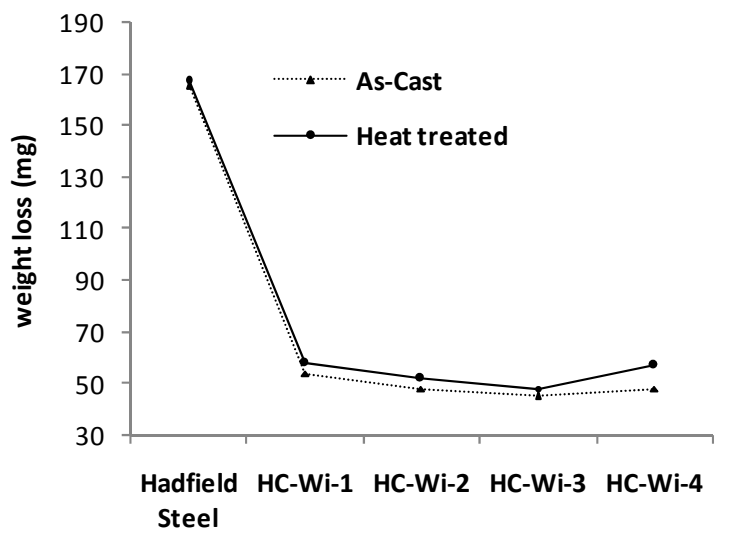

Figure 6. Weight loss of HC-Wi alloys and Hadfield steel.

2) The presence of chromium carbide lowers the impact toughness of HC-Wi alloys compared to Hadfield austenitic manganese steel.

3) The mechanical properties of HC-Wi alloys are affected by the distribution of the hard second phase particles in the austenite.

4) For practical application where replacements of worn-out mechanical components result to frequent plant shutdown with associated high maintenance cost, the more expensive HC-Wi alloys are recommended over the cheaper Hadfield manganese steel.

\section{REFERENCES}

[1] E. Bayraktar, F. A. Khalid and C. Levaillant, "Deformation and Fracture Behaviour of High Manganese Austenitic Steel," Journal of Materials Processing Technology, Vol. 147, No. 2, 2004, pp.145-154. doi:10.1016/j.jmatprotec.2003.10.007

[2] I. Karaman, H. Sehitoglu, A. J. Beaudoin, Y. Chumlyakov, H. J. Maier and C. N. Tomé, "Modeling the Deformation Behavior of Hadfield Steel Single and Polycrys- tals Due to Twinning and Slip,” Acta Materialia, Vol. 48, No. 9, 2000, pp. 2031-2047. doi:10.1016/S1359-6454(00)00051-3

[3] A. K. Srivastava and K. Das, "Microstructural and Mechanical Characterization of in Situ $\mathrm{TiC}$ and $(\mathrm{Ti}, \mathrm{W}) \mathrm{C}$ Reinforced High Manganese Austenitic Steel Matrix Composites," Materials Science \& Engineering: A, Vol. 516, No. 1-2, 2009, pp. 1-6. doi:10.1016/j.msea.2009.04.041

[4] A. Maksim and H. Irina, "Thermophysical Properties and Thermal Shock Resistance of Chromium Carbide Based Cermets," Proceedings of the Estonian Academy of Sciences, Engineering, Vol. 12, No. 4, 2006, pp. 358-367.

[5] W. Shizhong, J. Zhu and L. Xu, "Investigation on Wear Behaviors of High-Vanadium High-Speed Steel Compared with High-Chromium Cast Iron under Rolling Contact Condition,” Materials Science and Engineering: A, Vol. 434, No. 1-2, 2006, pp. 641-648.

[6] Y. Uematsu, K. Tokaji, K. Nishigaki, D. Okajima and M. Ogasawara, "Effects of HIP and Forging on Fracture Behaviour in Cast Iron with Spheroidal Vanadium Carbides Dispersed within Martensitic-Matrix Microstructure,” Materials Science and Engineering: A, Vol. 527, No. 10-11, 2010, pp. 2621-2628. doi:10.1016/j.msea.2010.01.067

[7] J. O. Agunsoye, V. S. Aigbodion and O. S. Sanni, “Effect of Heat Treatment on Microstructure and Mechanical Properties of NF6357A Cast Alloy for Wear Resistance Application,” Journal of Minerals and Materials Characterization and Engineering, Vol. 10, No. 11, 2011, pp. 1077 1086.

[8] J.-P. Breyer and W. Gisèle, "Metallurgy of High Chromium-Molybdenum White Iron and Steel Rolls,” In: R. B. Corbett, Ed., Rolls for the Metalworking Industries, Warendale, Pittsburgh, 2002, pp. 29-40.

[9] S. A. Balogun, D. E. Esezobor and J. O. Agunsoye, "Effect of Melting Temperature on the Wear Characteristics of Austenitic Manganese Steel,” Journal of Minerals and Materials Characterization and Engineering, Vol. 7, No. 3, 2008, pp. 277-289. 